\title{
Taq1B CETP Polymorphism and Cardiovascular Risk in an Endogamous Population of Diabetic Men: A Study in Santa Rosa Del Conlara, San Luis, Argentina
}

\author{
Susana Siewert ${ }^{1}$, Irma Gonzalez ${ }^{1}$, Sergio Filipuzzi², Dario C. Ramirez ${ }^{3}$, Marta S. Ojeda ${ }^{{ }^{*}}$ \\ ${ }^{1}$ Laboratory of Diabetes, Department of Biochemistry and Biological Sciences, School of Chemistry, \\ Biochemistry and Pharmacy, National University of San Luis, San Luis, Argentina \\ ${ }^{2}$ Hospital of Santa Rosa, Government of the Province of San Luis, Santa Rosa del Conlara, Argentina \\ ${ }^{3}$ Laboratory of Experimental Medicine and Therapeutics, IMIBIO-SL-National Bureau of Science and Technology \\ (CONICET) \& National University of San Luis, San Luis, Argentina \\ Email: msojeda@unsl.edu.ar, ramirezlabimibiosl@ymail.com
}

Received 10 April 2015; accepted 17 May 2015; published 20 May 2015

Copyright $(2015$ by authors and Scientific Research Publishing Inc.

This work is licensed under the Creative Commons Attribution International License (CC BY).

http://creativecommons.org/licenses/by/4.0/

(c) (i) Open Access

\section{Abstract}

Objectives: Type 2 diabetes mellitus (T2DM) patients are at increased risk of cardiovascular diseases (CVDs). Several polymorphisms in the cholesterol ester transfer protein (CETP) gene have been reported. The aim of this study was to determine the distribution and effect of the Taq1B polymorphism in the CETP gene on clinical and biochemical indicators of CVD risk in a population of endogamous-T2DM men. Methods: 102 men (57.5 \pm 9.3 years old) inhabitants of Santa Rosa del Conlara, San Luis, Argentina, were recruited and assigned into two groups (22 control and 80 T2DM). Further, these two groups were subdivided according to their Taq1B CETP gene genotypes (i.e., B1B1, B1B2 and B2B2). Clinical and fasting-plasma biochemical indicators of CVD risk were measured and their association with the B1 allele was determined. Results: Compared to control, T2DM men had more central obesity, hypertension, atherogenic index, insulin resistance and poorly controlled diabetes. Compared to T2DM men having the B2 allele, those T2DM men having the B1 allele have increased risk of CVD as assessed by systolic blood pressure (156 \pm 16.0 vs $135.8 \pm 19.2, p=0.015)$, atherogenic index $(6.15 \pm 1.3$ vs $4.4 \pm 0.7, p=0.0008)$, HDL-c levels (38.9 \pm 5.3 vs $64.4 \pm 8.2, p<0.0001$ ) and insulin resistance (HOMA-IR, $5.78 \pm 3.0$ vs $2.4 \pm 0.78, p=0.004$ ). Interestingly, only body mass index $(r=-0.559, p=0.01)$ and HDL-c concentration $(r=-0.492, p=$ 0.02) negatively correlated with CVD risk in the endogamous population of B1B1 and B1B2 T2DM men. Conclusion: The B1 allele of the CETP gene predicts cardiovascular complications in an

\footnotetext{
${ }^{*}$ Corresponding author.
}

How to cite this paper: Siewert, S., Gonzalez, I., Filipuzzi, S., Ramirez, D.C. and Ojeda, M.S. (2015) Taq1B CETP Polymorphism and Cardiovascular Risk in an Endogamous Population of Diabetic Men: A Study in Santa Rosa Del Conlara, San Luis, Argentina. Journal of Diabetes Mellitus, 5, 123-134. http://dx.doi.org/10.4236/jdm.2015.52015 
endogamous population of T2DM men.

Keywords Cholesteryl Ester Transfer Protein, Taq1B Polymorphism, Endogamous Type 2 Diabetic Men,
Cardiovascular Disease Risk, Santa Rosa del Conlara-San Luis-Argentina

\section{Introduction}

Type 2 diabetes mellitus (T2DM) patients have an increased risk of developing cardiovascular diseases (CVDs) [1]. This increased risk of CVDs is associated with alterations in the lipid profile in plasma. Indeed, lipoprotein profile in T2DM patients is characterized by increased plasma concentrations of triglyceride (TG)-rich lipoprotein particle remnants, small dense low-density lipoprotein-cholesterol (LDL-c) particles, but decreased concentrations and size of high-density lipoprotein-cholesterol (HDL-c) [2]. Therefore, changes in the traffic and tissue deposition of lipids in T2DM patients may predict the risk of CVDs.

Cholesteryl ester transfer protein (CETP) is one of the major proteins that regulate the exchange of lipids between circulation and tissues [3] [4]. CETP regulates the bidirectional exchange of cholesteryl esters (CE) and TG between all plasma lipoprotein particles [2] [5]. CETP activity results in an overall transfer of CEs from HDL-c, an Apo-A1-containing lipoprotein, to apolipoprotein B (apoB) contained in very-low-density lipoprotein (VLDL) and LDL-c, which causes an atherogenic lipid profile [3]. Therefore, increased CETP protein and/or activity in humans may cause a lipid profile that is potentially antiatherogenic [6] [7]. Because CETP plays a central role in the composition and size of HDL-c, subtle changes in its synthesis, and consequently activity, may alter CVD risk [6] [8] [9].

Single nucleotide polymorphisms (SNPs) in the CETP gene that determine decreased CETP activity and/or mass are associated with elevated concentrations of HDL-c and decreased CVD risk [4]. A number of SNPs have been described in the CETP gene (Accession id: ENSG00000087237) [10]-[12]. Most of these SNPs are associated with low plasma CETP protein and high HDL-c concentrations in plasma [10] [13]. Interestingly, environmental factors have been shown to contribute to the association strength between these SNPs of the CETP gene and HDL-c concentrations [10] [14]-[16]. One of the most frequent SNPs in the CETP gene is that located at the $227^{\text {th }}$ nucleotide in its first intron (rs708272 or Taq1B, NG_008952.1:g.5454G>A) [17]. This SNP results in the disruption of a restriction site for the restriction enzyme Taq1 (B2 allele) [10]. The heterozygous B1B2 genotype is the most frequent in most populations [18]. The Taq1B polymorphism is characterized by a silent base change from a G (designed as B1) to an A (designed as B2) nucleotide, at the $277^{\text {th }}$ nucleotide in the intron 1 of the CETP gene, and possesses a restriction site for the endonuclease Taq1. The B2 allele of this SNP (absence of restriction site) has been associated with decreased CETP mass, increased HDL-c concentrations and decreased cardiovascular risk and metabolic syndrome [6] [14] [17] [19]. Therefore, the Taq1B polymorphism of the CETP gene is likely to have an impact on lipid profile and thus determine CVD risk in T2DM patients, but reports on the subject in endogamous populations are limited [20] [21]. Importantly, endogamy is an important factor that may explain the increased incidence of genetic-associated metabolic complications in T2DM populations [18] [21] [22].

The results from epideliological studies have, like-wise, been equivocal, with some studies suggesting that the association of the CETP Taq1B SNP with plasma HDL-c concentrations may be population specific [23] [24] and highly influenced by gender [13], environmental factors such as diet, alcohol consumption [25] and smoking [26]. In the general population, the Taq1B polymorphism of the CETP gene is known to affect both CETP activity and HDL-c concentrations, perhaps independently [27]. In a population of 406 T2DM patients, Durlach et al. [20] showed that the Taq1B polymorphism of the CETP gene has an impact on HDL-c concentrations in male patients only, female displayed equally high concentrations independent of genotype. That study showed that B2-homozygotes men had less incidence of CVD. In addition, the association of CETP Taq1B genotype with plasma HDL-c and CVD risk may be population specific, and highly influenced by dietary, environmental and genetic backgrounds [6]. Indeed, a study in a Tunisian population of 172 T2DM patients shown that the B1 allele was more associated with low HDL-c concentrations than other populations [6]. The association between 
the B2 allele and microangiopathy in a French and a Japanese population of T2DM patients showed contrasting results regarding the effect of gender [28]. These and other studies suggested the importance of determining in specific ethnic populations the association between gender, CETP Taq1B genotypes, biochemical profile and CVD risk in order to improve therapeutic and interventions.

The population of Santa Rosa del Conlara, a small city ( 4000 inhabitants) located in the northwest region of the province of San Luis-Argentina, has shown an incidence of T2DM in adults of 13.5\%, which is higher than any other region in the country (i.e., 7.5\%) (MS Ojeda, et al. unpublished results). These patients have increased risk of CVDs, however whether a particular Taq1B genotype, and associated atherogenic lipid profile, may affect the risk of CVDs in this population is unknown.

Herein we investigated the impact of Taq1B genotypes on clinical and biochemical parameters that may determine changes in the risk of CVDs in an endogamous population of T2DM men. Studies like this are rare in the literature and will provide interesting data regarding the association of the CETP Taq1B genotype and CVD risk in a unique population of T2DM men that will help improving health care policies. We found that, compared to control patients, endogamous T2DM men have more central obesity, atherogenic index (AI), insulin resistance, lower HDL-c, and higher systolic blood pressure (SBP). Although endogamous T2DM men have the same frequency of Taq1B allele and genotypes of the CETP gene, those with the B1 allele are at increased risk of CVDs, more likely due to an atherogenic lipid profile, insulin resistance and hypertension.

\section{Methods}

\subsection{Population Studied}

The present study was carried out in accordance with the guidelines of the Helsinki Declaration. Hundred and two (102) un-related men (57.5 \pm 9.3 years old) inhabitants of Santa Rosa del Conlara were enrolled during their regular annual health check-up. The protocol followed in this study was approved by the local Institutional Review Board, and a written informed consent was obtained from each man to be enrolled. During an initial interview with each patient, they were asked for diseases, medication and smoking histories. Exclusion criteria included liver, kidney and thyroid diseases, as well as the use of anti-lipemic drugs. The American Diabetes Association's criteria [29] were used to grouping this population in control $(n=22,55.4 \pm 9.7$ years old $)$ and T2DM ( $\mathrm{n}=80,58.2 \pm 9.1$ years old) patients.

\subsection{Clinical and Anthropometric Measurements}

For each subject enrolled, height (meters), weight $(\mathrm{Kg})$ and waist and hip circumferences $(\mathrm{cm})$ were recorded following routine procedures. Height and weight were measured to the nearest $0.5 \mathrm{~cm}$ and $0.1 \mathrm{~kg}$, respectively. The body mass index (BMI) was calculated as weight divided by height squared $\left(\mathrm{Kg} / \mathrm{m}^{2}\right)$. Those men with a BMI equal or greater than $30 \mathrm{Kg} / \mathrm{m}^{2}$ were considered as obese. Waist/hip ratio (WHR) was calculated as a measurement of central obesity. Blood pressure was measured in the right arm after a 10-min rest in the supine position. Hypertension was diagnosed as a systolic blood pressure (SBP) equal or greater than $130 \mathrm{mmHg}$ and a diastolic blood pressure equal or greater than $85 \mathrm{mmHg}$.

\subsection{Blood Sampling}

Fating blood samples were obtained from patients that had fasted for at least $12 \mathrm{~h}$. Blood was collected in plastic tubes containing $0.1 \%$ EDTA. Plasma and blood cells (pellets) were separated by centrifugation at $2400 \mathrm{rpm}$ for $20 \mathrm{~min}$ at room temperature. After separation, plasma and packed blood cells were aliquoted and stored at $-20^{\circ} \mathrm{C}$ until use.

\subsection{Biochemical Measurements}

Fasting plasma glucose (FPG) was measured by using a glucose oxidase method with a commercial enzymatic kit (Wiener Laboratories, Rosario, Argentina). Fasting plasma insulin (INS) concentration was measured by an electrochemiluminiscence immunoassay (Roche Diagnostics, Mannheim, Germany). The homeostasis model assessment of insulin resistance (HOMA-IR) was calculated as follow: fasting insulin $(\mu \mathrm{IU} / \mathrm{mL}) \times$ fasting glucose (mmol/L)/22.5. Glycated hemoglobin (HbA1c) concentration was measured with a coupled ionic-exchange 
chromatography/spectrophotometric assay (BioSystems, Barcelona, Spain). Total cholesterol (TC), TG and HDL-c concentrations were measured using commercial kits by following manufacturer's instructions (Wiener Laboratories). LDL-c was calculated with the Friedewald formula [30]. Apo A-I concentration in the plasma was measured with an immunoturbidimetric assay (Diffu-Plate, Biocientífica, Buenos Aires). The atherogenic index (AI) was calculated by using the following formula: TC (mg/dL)/HDL-c (mg/dL).

\subsection{Analysis of Taq1B Polymorphism of the CETP Gene}

DNA was extracted from packed blood cells using the Qiagen QiAmp Mini Kit (Valencia, CA). CETP TaqB1 alleles were determined as described by Fumeron et al. [31]. Briefly, a 535 bp fragment in the first intron of the CETP gene (GenBank accession number NM_000078) that includes the rs708272 SNP was amplified by the polimerasa chain reaction (PCR). Oligonucleotide primers used here were as follow: forward 5'-CACTAGCCCAGAGAGAGGAGTGCC-3' and reverse 5'-CTGAGCCCAGCCGCACACTAAC-3'. Each amplification reaction included 100 ng of genomic DNA, 20 pmol of each PCR primer and 1 unit of AmpliTaq Gold DNA polymerase (Perkin-Elmer, Waltham, MA). These reactions were performed in a buffer containing $1.5 \mathrm{mmol} / \mathrm{L}$ $\mathrm{MgCl}_{2}, 50 \mathrm{mmol} / \mathrm{L} \mathrm{KCl}, 20 \mathrm{mmol} / \mathrm{L}$ Tris-HCl (pH 8.4), and $200 \mathrm{pmol} / \mathrm{L}$ of each deoxynucleotide triphosphate. The template DNA was denatured for 3 minutes at $95^{\circ} \mathrm{C}$ before undergoing 30 cycles of amplification. Each amplification cycle included: denaturation for 30 seconds at $95^{\circ} \mathrm{C}$, primer annealing for 30 seconds at $60^{\circ} \mathrm{C}$, and extension for 45 seconds at $72^{\circ} \mathrm{C}$; followed by a final extension at $72^{\circ} \mathrm{C}$ for 5 minutes.

The Taq1B allele of the CETP gene in each sample was determined by digesting $10 \mu \mathrm{L}$ of the PCR product with one unit of Taq1 restriction endonuclesase (Promega, Madison, WI) for 2 hours at $65^{\circ} \mathrm{C}$. The resulting digest was separated by electrophoresis in a $2 \%$ agarose gel. The digestion products were revealed by ethydium bromide staining of the gel and visualized under ultraviolet light. Visualization of two DNA fragments of the Taq1 treated amplicon at 174 and 361 bp indicates a B1 allele (presence of the restriction site), whereas an intact 535 bp indicates a B2 allele (absence of the restriction site). See Figure 1.

\subsection{Statistical Analysis}

Chi-square test was used to check adjustment of the data to the Hardy-Weinberg equilibrium and to compare the allelic frequencies between control and T2DM men. These allelic frequencies in our patients were in a HardyWeinberg equilibrium. Statistical analyses were first performed for all patients and then for control and T2DM men by separate. Data are shown as either mean values \pm standard deviation (SD), absolute values or percentages (\%). To analyze the association between the B1 allele of the CETP gene and indicators of CVD risk a Student $t$-test was used when variables were continuous, whereas a Fisher's exact test was used for the categorical variables. STATA version 6 (SataCorp LP, College Station, TX) was used for statistics. A $p<0.05$ was considered to be statically significant.

\section{Results}

\subsection{Clinical, Anthropometric and Biochemical Characteristics of the Study Population}

Hundred and two (102) men living in Santa Rosa del Conlara, were enrolled in this study. This study included 22 control and 80 T2DM unrelated men. Clinical, anthropometric and biochemical data are shown Table 1. Enrolled patients were $57.5 \pm 9.3$ years old and had a BMI of $30.0 \pm 4.2 \mathrm{Kg} / \mathrm{m}^{2}$. Compared with control patients,

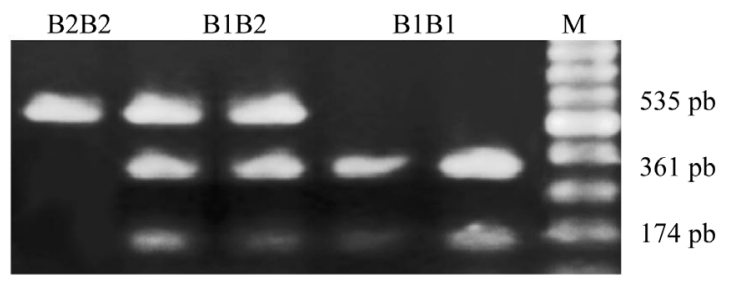

Figure 1. Agarose-gel electrophoresis showing typical patterns of the Taq1B polymorphism of the CETP gene. $\mathrm{M}$, molecular weight marker. 
Table 1. Selected clinical, anthropometric and biochemical indicators of CVD risk.

\begin{tabular}{|c|c|c|c|c|}
\hline & All $(n=102)$ & Control $(n=22)$ & T2DM $(n=80)$ & $p$ \\
\hline Age (years) & $57.5 \pm 9.3^{\dagger}$ & $55.4 \pm 9.7$ & $58.2 \pm 9.1$ & 0.2090 \\
\hline BMI $\left(\mathbf{k g} / \mathrm{m}^{2}\right)^{\ddagger}$ & $30.0 \pm 4.2$ & $27.1 \pm 4.7$ & $30.7 \pm 3.6$ & 0.0002 \\
\hline WHR & $0.90 \pm 0.1$ & $0.77 \pm 0.1$ & $0.93 \pm 0.1$ & $<0.0001$ \\
\hline SBP (mmHg) & $137.7 \pm 19.8$ & $125.7 \pm 10.5$ & $141.0 \pm 20.5$ & 0.0010 \\
\hline TG (mg/dL) & $254.0 \pm 106.0$ & $125.6 \pm 11.4$ & $281.3 \pm 96.5$ & $<0.0001$ \\
\hline TC (mg/dL) & $221.0 \pm 50.3$ & $180.8 \pm 32.6$ & $232.0 \pm 48.8$ & $<0.0001$ \\
\hline LDL-c (mg/dL) & $124.8 \pm 28.0$ & $99.7 \pm 25.0$ & $131.5 \pm 25.0$ & $<0.0001$ \\
\hline HDL-c (mg/dL) & $43.3 \pm 9.1$ & $49.7 \pm 3.1$ & $41.5 \pm 9.5$ & $<0.0001$ \\
\hline Apo A-I (mg/dL) & $125.8 \pm 7.4$ & $120.3 \pm 6.4$ & $131.4 \pm 8.5$ & 0.3240 \\
\hline AI & $5.3 \pm 1.6$ & $3.57 \pm 0.8$ & $5.76 \pm 1.5$ & $<0.0001$ \\
\hline FPG (mg/dL) & $180.0 \pm 70.8$ & $88.4 \pm 9.4$ & $194.4 \pm 68.3$ & $<0.0001$ \\
\hline HbA1c (\%) & $8.5 \pm 2.4$ & $5.6 \pm 0.6$ & $8.5 \pm 2.3$ & $<0.0001$ \\
\hline HOMA-IR & $4.66 \pm 4.3$ & $2.33 \pm 1.1$ & $5.30 \pm 4.7$ & 0.0040 \\
\hline
\end{tabular}

${ }^{\dagger}$ Data are shown as mean $\pm \mathrm{SD} ;{ }^{\ddagger}$ Abbreviations used here are: AI, atherogenic index = TC(mg/dL)/HDL-c(mg/dL); Apo, apolipoprotein; BMI, body mass index; FPG, fasting plasma glucose; HbA1c, glycated hemoglobin; HDL-c, high density lipoprotein-cholesterol; HOMA-IR, homeostasis model assessment of insulin resistance; LDL-c, low density lipoprotein-cholesterol; SBP, systolic blood pressure; TC, total cholesterol; TG, triglycerides; WHR, waist-to-hip ratio.

T2DM men had higher BMI, WHR, and SBP. These data suggest T2DM endogamous men included in this study are obese and hypertensive. Compared to control, T2DM men had higher FPG, HbA1c and HOMA-IR, which together indicate that these patients were insulin resistant and also that their glycemia was poorly controlled. Compared to control, T2DM patients had a larger AI, higher fasting concentrations of atherogenic lipids (i.e., TC, TG and LDL-c) and lower concentrations of HDL-c. These data suggest that these patients had increased risk of CVD, such as atherosclerosis.

\subsection{Genotype Frequencies}

Table 2 shows the genotype and allelic frequencies (\%) and absolute number of patients having each genotype in all, control and T2DM men. The observed allelic frequencies were in Hardy-Weinberg equilibrium. DNA analysis showed that $22.5 \%$ of all our patients were homozygous carriers of the B1 allele (B1B1 genotype), whereas $67.4 \%$ were heterozygous carriers of the B1 and B2 alleles (B1B2 genotype). Only 9.8\% of all our patients were homozygous carriers of the B2 allele (B2B2 genotype). Genotype frequencies, as percentages, of the B1B1:B1B2:B2B2 in control and T2DM men were 13.6:77.3:9.1 and 25:65:10, respectively. Genotype and allele frequencies between control versus T2DM patients were not different.

\subsection{Association between CVD Risk Indicators and Taq1B Polymorphism of the CETP Gene in the Population of Endogamous Men}

Table 3 shows the association of Taq1B polymorphism of the CETP gene and CVD risk indicators in control and T2DM men by separate. Compared to control men having the B2B2 genotype, those control patients having the B1 allele had more central obesity (WHR, $p=0.025)$, lower HDL-c $(p=0.004)$ and insulin resistance (HOMA-IR, $p=0.025)$. With the exception of WHR, the values of HDL-c $(p<0.0001)$ and HOMA-IR $(p=$ 0.004) were more significant in T2DM patients with the B1B1/B1B2 genotypes than in those T2DM with the B2B2 genotype. The presence of at least one B1 allele caused T2DM men having higher SBP $(p=0.015)$, AI ( $p$ $=0.0008)$, TC $(p=0.01)$ and TG $(p=0.003)$, however, these indicators were not affected by the TaqB1 CETP genotype in control men. Supplementary Table 1 shows the analysis of the association of CVD risk in control 
Table 2. Genotype and allelic frequencies.

\begin{tabular}{|c|c|c|c|c|c|}
\hline & All $(n=102)$ & Control $(n=22)$ & T2DM $(n=80)$ & OR (95\% CI) & $p$ \\
\hline \multicolumn{6}{|l|}{ Genotypes $^{\dagger}$} \\
\hline B2B2 & $10(9.8 \%)$ & 2 (9.1\%) & $8(10.0 \%)$ & 1 & \\
\hline B1B1 & $23(22.5 \%)$ & $3(13.6 \%)$ & $20(25.0 \%)$ & $1.667(0.232-11.934)$ & $0.608^{\S}$ \\
\hline B1B2 & $69(67.4 \%)$ & 17 (77.3\%) & $52(65.0 \%)$ & $0.765(0.147-3.957)$ & 0.748 \\
\hline B1B1/B1B2 & 92 (89.9\%) & 20 (90.9\%) & 72 (90.9\%) & $0.900(0.176-4.580)$ & 0.898 \\
\hline \multicolumn{6}{|l|}{ Alleles $^{\ddagger}$} \\
\hline B2 & 0.44 & 0.48 & 0.42 & 1 & \\
\hline B1 & 0.56 & 0.52 & 0.57 & $0.789(0.456-1.397)$ & $0.517^{\circ}$ \\
\hline
\end{tabular}

${ }^{\dagger}$ Percentages, odds ratio (OR) and p with respect to B2B2 genotype (shown as 1.0); ${ }^{\ddagger}$ Percentages, OR and p with respect to B2 allele (shown as 1.0 ); ${ }^{\S}$ Significance when comparing the frequency of the B1B1 and B1B2 with respect to the B2B2 genotype; "Significance when comparing the frequency of the B1 allele with respect to the B2 allele.

Table 3. Selected indicators of CVD risk according Taq1B genotypes of CETP in the study population ${ }^{\dagger}$.

\begin{tabular}{ccccccc}
\hline & \multicolumn{3}{c}{ Control (n= 22) } \\
\hline Variables & $\begin{array}{c}\text { B1B1/B1B2 } \\
\mathbf{n}=\mathbf{2 0}(90 \%)\end{array}$ & $\begin{array}{c}\text { B2B2 } \\
\mathbf{n}=\mathbf{2}(9 \%)\end{array}$ & $\boldsymbol{p}$ & $\begin{array}{c}\text { B1B1/B1B2 } \\
\mathbf{n}=\mathbf{7 2}(90 \%)\end{array}$ & $\begin{array}{c}\text { B2B2 } \\
\mathbf{n}=\mathbf{8}(10 \%)\end{array}$ & $\boldsymbol{p}$ \\
\hline Age (years) & $56.1 \pm 9.8$ & $47.0 \pm 1.4$ & 0.084 & $58.7 \pm 7.2$ & $53.2 \pm 7.5$ & 0.108 \\
Smoking Status & $12(60 \%)$ & $2(100 \%)$ & - & $22(30.5 \%)$ & $3(37.5 \%)$ & - \\
BMI (kg/m $\left.\mathbf{m}^{2}\right)$ & $27.5 \pm 4.7$ & $24.2 \pm 1.5$ & 0.190 & $32.3 \pm 3.3$ & $30.6 \pm 3.7$ & 0.445 \\
WHR & $0.78 \pm 0.09$ & $0.67 \pm 0.02$ & 0.025 & $0.94 \pm 0.06$ & $0.92 \pm 0.06$ & 0.428 \\
SBP & $126.1 \pm 10.2$ & $122.6 \pm 11.3$ & 0.599 & $156.1 \pm 16.0$ & $135.8 \pm 19.2$ & 0.015 \\
AI & $4.1 \pm 0.2$ & $4.3 \pm 0.6$ & 0.280 & $6.15 \pm 1.3$ & $4.4 \pm 0.7$ & 0.0008 \\
TC (mg/dL) & $208.1 \pm 19.7$ & $188.1 \pm 25.6$ & 0.156 & $248.6 \pm 37.7$ & $212.2 \pm 45.6$ & 0.01 \\
TG (mg/dL) & $126.6 \pm 11.2$ & $115.2 \pm 3.3$ & 0.055 & $300.6 \pm 78.2$ & $272.6 \pm 44.2$ & 0.003 \\
LDL-c (mg/dL) & $109.8 \pm 15.5$ & $102.5 \pm 1.9$ & 0.384 & $141.1 \pm 21.4$ & $135.3 \pm 26.1$ & 0.499 \\
HDL-c (mg/dL) & $43.7 \pm 3.4$ & $50.5 \pm 5.0$ & 0.004 & $38.9 \pm 5.3$ & $64.4 \pm 8.2$ & $<0.0001$ \\
FPG (mg/dL) & $88.4 \pm 9.9$ & $85.5 \pm 5.2$ & 0.579 & $198.8 \pm 69.4$ & $182.4 \pm 39.5$ & 0.513 \\
INS mU/ml & $11.5 \pm 2.9$ & $6.7 \pm 1.6$ & 0.006 & $21.8 \pm 10.7$ & $19.6 \pm 7.0$ & 0.563 \\
HOMA-IR & $2.46 \pm 1.1$ & $1.05 \pm 0.36$ & 0.025 & $5.78 \pm 3.0$ & $2.40 \pm 0.78$ & 0.004 \\
HbA1c & $5.6 \pm 0.6$ & $5.1 \pm 0.5$ & 0.212 & $8.6 \pm 2.4$ & $7.4 \pm 1.0$ & 0.142 \\
\hline
\end{tabular}

${ }^{\dagger}$ Data shown as percentage of the total, absolute values and mean values \pm SD; ${ }^{\ddagger}$ Abbreviations used here are: AI, atherogenic index; Apo, apolipoprotein; BMI, body mass index; FPG, fasting plasma glucose; HbA1c, glycated hemoglobin; INS, insulin; HDL-c, high-density lipoprotein-cholesterol; HOMA-IR, homeostasis model assessment-insulin resistance index; LDL-c, low density lipoprotein-cholesterol; SBP, systolic blood pressure; TC, total cholesterol; TG, triglycerides; WHR, waist/hip ratio.

and T2DM men having either a B1B1/B1B2 or B2B2 genotype. Data shown indicate that SBP $(p=0.002)$ and $\mathrm{AI}(p<0.0001)$ are different between control and T2DM patients having at least one B1 allele (i.e., B1B1 or B1B2 genotype). TC ( $p<0.0001$ vs $p=0.03)$, TG ( $p<0.0001$ vs $p=0.002)$, LDL-c $(p<0.0001$ vs $p=0.006)$, HDL-c $(p<0.0001$ vs $p=0.002)$, FPG ( $p<0.0001$ vs $p=0.0007$ ), insulin (INS, $p=0.003$ vs $p=0.005$ ) and HbA1c $(p<0.0001$ vs $p=0.009)$ were more significant when B1B1/B1B2 control and T2DM were compared, regarding the same comparison between B2B2 control and T2DM men. The HOMA-IR difference was more significant in control/T2DM men harboring the B2B2 genotype $(p=0.0002)$ than in control/T2DM men having 
the B1B1/B1B2 genotypes $(p=0.002)$.

\subsection{Correlation Analysis of the B1 Allele and CVD Risk Indicators in T2DM Men}

Table 4 shows a correlation analysis between the B1 allele and the most common CVD risk indicators in T2DM men. Data had a normal distribution according the Kolmogorov-Smimov test. As expected, the B1 allele negatively correlated with HDL-c $\left(\mathrm{r}=-0.492, \mathrm{r}^{2}=0.242, p=0.02\right)$ and BMI $\left(\mathrm{r}=-0.559, \mathrm{r}^{2}=0.313, p=0.01\right)$ in T2DM men, but not in control men. Our analysis did not show any correlation of the B1 allele of the CETP gene and other common CVD risk indicators, such as WHR, SBP, AI and HOMA-IR.

\section{Discussion}

We studied a possible association between Taq1B CETP genotypes and indicators of CVD risk in an endogamous population of control and T2DM men inhabitant of Santa Rosa del Conlara City, San Luis, Argentina. This population is unique because the prevalence of T2DM in this region is almost twice as any other region in the country (13.5\% vs 7.5\%) (Ojeda, MS, unpublished data). Importantly, our data suggest that those T2DM men having a $\mathrm{B} 1$ allele of the CETP gene have a lipid profile consistent with an increased risk of CVDs.

A number of previous studies have shown that the Taq1B polymorphism of the CETP gene is associated with vascular complications of T2DM ([1] [28] and references therein). Changes in the synthesis of CETP lead to changes in the concentration, size and composition of HDL-c particles [5]. Another research team reported that the B1B1 and B2B2 genotypes of the CETP gene were associated with high and low plasma mass/activity of CETP, respectively [6] [13]. Besides the uniqueness of our study carried out in an endogamous population of control and T2DM men, our data show a relationship between the different Taq1B alleles of the CETP gene and anthropometric, clinical and biochemical variables in T2DM unrelated men. Kawasaki et al. [32] reported an association between Taq1B polymorphism of CETP and HDL-c plasma concentrations in T2DM patients. Moreover, ethnicity plays an important role in the association between CETP polymorphisms, T2DM incidence and CVD risk [18] [28] [33]. Our present study goes beyond those studies by showing the frequency and distribution of Taq1B-CETP alleles and genotypes in a well defined and homogeneous population of endogamous T2DM unrelated men.

Table 4. Correlation between the B1 allele of the CETP gene and selected indicators of CVD risk ${ }^{\dagger}$.

\begin{tabular}{|c|c|c|c|c|}
\hline & & $r$ & $r^{2}$ & $p$ \\
\hline \multicolumn{5}{|c|}{ Indicators of CVD risk $^{\ddagger}$} \\
\hline \multirow{2}{*}{$\mathbf{B M I}^{\S}$} & Control & 0.868 & 0.753 & 0.330 \\
\hline & T2DM & -0.559 & 0.313 & 0.010 \\
\hline \multirow{2}{*}{ WHR } & Control & 0.693 & 0.480 & 0.512 \\
\hline & T2DM & -0.088 & 0.008 & 0.710 \\
\hline \multirow{2}{*}{ SBP } & Control & 0.832 & 0.692 & 0.374 \\
\hline & T2DM & -0.159 & 0.025 & 0.501 \\
\hline \multirow{2}{*}{ HDL-c } & Control & 0.945 & 0.893 & 0.212 \\
\hline & T2DM & -0.492 & 0.242 & 0.020 \\
\hline \multirow{2}{*}{ AI } & Control & -0.988 & 0.977 & 0.097 \\
\hline & T2DM & 0.046 & 0.002 & 0.846 \\
\hline \multirow{2}{*}{ HOMA-IR } & Control & -0.776 & 0.602 & 0.434 \\
\hline & T2DM & -0.128 & 0.0002 & 0.957 \\
\hline
\end{tabular}

\footnotetext{
${ }^{\dagger}$ The distribution of the population of data was determined using the Kolmogorov-Smirnov test. Data had a normal distribution (homogeneous). ${ }^{\ddagger}$ The correlation between the Taq1B B1 allele of the CETP gene and selected indicators of CVD risk was determined using the Spearman's test (nonparametric). $r$, is the correlation coefficient and $r^{2}$ is the coefficient of determination. ${ }^{\S}$ Abbreviations used here are: AI, atherogenic index; BMI, body mass index; HDL-c, high density lipoprotein-cholesterol; HOMA-IR, homeostasis model assessment-insulin resistance index; SBP, systolic blood pressure; WHR, waist-to-hip ratio.
} 
Factors such as gender, life-styles, smoking status and BMI are known to affect the association between the Taq1B polymorphism of the CETP gene and risk of CVDs [16] [34] [35]. Our study showed an association between the B1 allele, central adiposity, hypertension and HDL-c concentrations in T2DM endogamous men. The frequencies (\%) of B1B1:B1B2:B2B2 genotypes in our T2DM men were 25:65:10, respectively, which was similar to that one reported in The Framingham Offspring Study [36] that showed a similar distribution of B1B1: B1B2:B2B2 (i.e., 30:51:19). In addition, Park et al. [37], in their Korean cohort reported similar B1B1:B1B2: B2B2 frequencies in men 35.5:50:14.5. Obviously, ethnic, cultural, demographic, geographic and nutritional factors may impact the association between Taq1B CETP genetic variants, lipid parameters and the incidence of CVD in T2DM men.

Durlach et al. [20] showed that T2DM patients with the B2 allele had significantly less CVD risk than those having the B1 allele of the CETP gene. Our study showed that those T2DM men having a B2B2 genotype had higher plasma HDL-c concentrations. These findings agree with the association between HDL-c concentrations and Taq1B polymorphism of the CETP gene in the Veterans Affairs HDL-c Intervention Trial [13]. However, men who have the B1 allele may be at increased risk for metabolic complications due to the larger central adiposity and altered distribution of cholesteryl esthers (CE) and TG [38]-[40]. The cholesterol exchange process from HDL to non-HDL lipoproteins is mediated by CETP that facilitates the incorporation of CE into TG-rich lipoproteins as part of the reverse cholesterol transport pathway [5]. Indeed, the beneficial effects of HDL-c on the cardiovascular system have been attributed to its ability to remove cellular cholesterol, as well as its anti-inflammatory, anti-oxidant and anti-thrombotic properties [41] [42]. All these properties of HDL-c can improve endothelial function and inhibit atherosclerosis, thereby reducing the risk of CVDs [43].

The association of the Taq1B CETP genotype and HDL-c concentrations is widely recognized in T2DM patients [44]-[46]; however, our population is unique in a number of aspects. For instance, its endogamous nature may explain the high incidence of T2DM, and CVD related death, among the adult population [22]. The present study in an endogamous population shows that the B1B1 and B1B2 genotypes are associated with lower HDL-C concentrations and increased CVD risk in T2DM men.

Our study suggests that our population of endogamous T2DM men having at least one Taq1 B1 allele of CETP gene are at increased risk of CVDs. In this regard, an association between CETP Taq1B polymorphism and HDL-c concentrations was more evident in T2DM patients with higher intake of total fat, saturated fat, and monosaturated fat. Lowering fat and increasing carbohydrate intake to keep the caloric balance may help reducing the effect of the B1 allele on HDL-c concentration and consequently reducing CVD risk [47]. Identification of T2DM B1 homozygous patients in this endogamous population will help deciding whether the treatment with inhibitors of CETP activity, such as anacetrapib [48] [49], may benefit by increasing HDL-c concentrations, and thus reducing CVD risk. On the other hand, cigarette smoking has been identified as an independent and preventable risk factor for CVDs. HDL-c is susceptible to oxidative modifications by cigarette smoking, which makes HDL-c become dysfunctional and lose its cardioprotective properties in smokers [50]. Thus, reducing cigarette smoking, one of the most preventable causes of CVD risk associated to CETP activity, especially in B1-homozygous T2DM patients in a genetically homogeneous population such as our endogamous population may be beneficial.

Consequently, aggressive management to modulate CETP mass and/or activity by nutritional (reducing fat intake and increasing carbohydrate intake), behavioural (reducing cigarette smoking) or pharmacological (inhibitors of CETP activity) means are required to reduce the risk of CVDs in T2DM men harbouring the B1 allele of the CETP gene [41]. Importantly, our study also emphasizes the importance of genotyping T2DM patients according the Taq1B polymorphism of the CETP gene in order to establish efficient prevention policies to reduce the risk of CVDs in T2DM patients. Finally, genotyping of the Taq1B polymorphism of the CETP gene can be of high predictive and interventional value of cardiovascular complications in our, and probably other, endogamous population of T2DM men.

\section{Acknowledgements}

This study was supported by a grant from the National University of San Luis and the Government of the Province of San Luis to MSO. DCR is an investigator of the National Bureau of Science and Technology (CONICET). 


\section{Disclosure}

Authors have not conflict of interest to disclose

\section{References}

[1] Pyorala, K., Laakso, M. and Uusitupa, M. (1987) Diabetes and Atherosclerosis: An Epidemiologic View. Diabetes/ Metabolism Reviews, 3, 463-524. http://dx.doi.org/10.1002/dmr.5610030206

[2] Thompson, J.F., Durham, L.K., Lira, M.E., Shear, C. and Milos, P.M. (2005) CETP Polymorphisms Associated with HDL Cholesterol May Differ from Those Associated with Cardiovascular Disease. Atherosclerosis, 181, 45-53. http://dx.doi.org/10.1016/j.atherosclerosis.2005.01.015

[3] Groener, J.E., Van Rozen, A.J. and Erkelens, D.W. (1984) Cholesteryl Ester Transfer Activity. Localization and Role in Distribution of Cholesteryl Ester among Lipoproteins in Man. Atherosclerosis, 50, 261-271. http://dx.doi.org/10.1016/0021-9150(84)90074-1

[4] Thompson, A., Di Angelantonio, E., Sarwar, N., et al. (2008) Association of Cholesteryl Ester Transfer Protein Genotypes with CETP Mass and Activity, Lipid Levels, and Coronary Risk. JAMA, 299, 2777-2788. http://dx.doi.org/10.1001/jama.299.23.2777

[5] Oliveira, H.C., Ma, L., Milne, R., et al. (1997) Cholesteryl Ester Transfer Protein Activity Enhances Plasma Cholesteryl Ester Formation. Studies in CETP Transgenic Mice and Human Genetic CETP Deficiency. Arteriosclerosis, Thrombosis, and Vascular Biology, 17, 1045-1052. http://dx.doi.org/10.1161/01.ATV.17.6.1045

[6] Chaaba, R., Hammami, S., Attia, N., et al. (2005) Association of Plasma Cholesteryl Ester Transfer Protein Activity and Polymorphism with Coronary Artery Disease Extent in Tunisian Type II Diabetic Patients. Clinical Biochemistry, 38, 373-378. http://dx.doi.org/10.1016/j.clinbiochem.2004.12.011

[7] Mohammadpour, A.H. and Akhlaghi, F. (2013) Future of Cholesteryl Ester Transfer Protein (CETP) Inhibitors: A Pharmacological Perspective. Clinical Pharmacokinetics, 52, 615-626. http://dx.doi.org/10.1007/s40262-013-0071-8

[8] Fielding, C.J. and Havel, R.J. (1996) Cholesteryl Ester Transfer Protein: Friend or Foe? The Journal of Clinical Investigation, 97, 2687-2688. http://dx.doi.org/10.1172/JCI118719

[9] Ridker, P.M., Pare, G., Parker, A.N., Zee, R.Y., Miletich, J.P. and Chasman, D.I. (2009) Polymorphism in the CETP Gene Region, HDL Cholesterol, and Risk of Future Myocardial Infarction: Genomewide Analysis among 18,245 Initially Healthy Women from the Women's Genome Health Study. Circulation: Cardiovascular Genetics, 2, 26-33. http://dx.doi.org/10.1161/CIRCGENETICS.108.817304

[10] Heidema, A.G., Feskens, E.J., Doevendans, P.A., et al. (2007) Analysis of Multiple SNPs in Genetic Association Studies: Comparison of Three Multi-Locus Methods to Prioritize and Select SNPs. Genetic Epidemiology, 31, 910-921. http://dx.doi.org/10.1002/gepi.20251

[11] Yamashita, S., Hirano, K., Sakai, N. and Matsuzawa, Y. (2000) Molecular Biology and Pathophysiological Aspects of Plasma Cholesteryl Ester Transfer Protein. Biochimica et Biophysica Acta (BBA)-Molecular and Cell Biology of Lipids, 1529, 257-275. http://dx.doi.org/10.1016/S1388-1981(00)00164-5

[12] Rejeb, J., Omezzine, A., Boumaiza, I., et al. (2012) Four Polymorphisms of Cholesteryl Ester Transfer Protein Gene and Coronary Stenosis in a Tunisian Population. Journal of Cardiovascular Medicine, 13, 546-553. http://dx.doi.org/10.2459/jcm.0b013e3283569b24

[13] Brousseau, M.E., O’Connor Jr., J.J., Ordovas, J.M., et al. (2002) Cholesteryl Ester Transfer Protein Taq IB2B2 Genotype Is Associated with Higher HDL Cholesterol Levels and Lower Risk of Coronary Heart Disease End Points in Men with HDL Deficiency: Veterans Affairs HDL Cholesterol Intervention Trial. Arteriosclerosis, Thrombosis, and Vascular Biology, 22, 1148-1154. http://dx.doi.org/10.1161/01.ATV.0000024566.57589.2E

[14] Robins, S.J., Lyass, A., Brocia, R.W., Massaro, J.M. and Vasan R.S. (2013) Plasma Lipid Transfer Proteins and Cardiovascular Disease. The Framingham Heart Study. Atherosclerosis, 228, 230-236. http://dx.doi.org/10.1016/j.atherosclerosis.2013.01.046

[15] Riemens, S., van Tol, A., Sluiter, W. and Dullaart, R. (1998) Elevated Plasma Cholesteryl Ester Transfer in NIDDM: Relationships with Apolipoprotein B-Containing Lipoproteins and Phospholipid Transfer Protein. Atherosclerosis, 140, 71-79. http://dx.doi.org/10.1016/S0021-9150(98)00111-7

[16] Heller, D.A., de Faire, U., Pedersen, N.L., Dahlen, G. and McClearn, G.E. (1993) Genetic and Environmental Influences on Serum Lipid Levels in Twins. The New England Journal of Medicine, 328, 1150-1156. http://dx.doi.org/10.1056/NEJM199304223281603

[17] Corsetti, J.P., Ryan, D., Rainwater, D.L., Moss, A.J., Zareba, W. and Sparks, C.E. (2010) Cholesteryl Ester Transfer Protein Polymorphism (TaqIB) Associates with Risk in Postinfarction Patients with High C-Reactive Protein and High-Density Lipoprotein Cholesterol Levels. Arteriosclerosis, Thrombosis, and Vascular Biology, 30, 1657-1664. 
http://dx.doi.org/10.1161/ATVBAHA.110.207977

[18] Li, Q., Huang, P., He, Q.C., Lin, Q.Z., Wu, J. and Yin, R.X. (2014) Association between the CETP Polymorphisms and the Risk of Alzheimer's Disease, Carotid Atherosclerosis, Longevity, and the Efficacy of Statin Therapy. Neurobiology of Aging, 35, 1513, e1513-1523.

[19] Sandhofer, A., Tatarczyk, T., Laimer, M., et al. (2008) The Taq1B-Variant in the Cholesteryl Ester-Transfer Protein Gene and the Risk of Metabolic Syndrome. Obesity, 16, 919-922.

http://dx.doi.org/10.1038/oby.2007.130

[20] Durlach, A., Clavel, C., Girard-Globa, A. and Durlach, V. (1999) Sex-Dependent Association of a Genetic Polymorphism of Cholesteryl Ester Transfer Protein with High-Density Lipoprotein Cholesterol and Macrovascular Pathology in Type II Diabetic Patients. The Journal of Clinical Endocrinology \& Metabolism, 84, 3656-3659. http://dx.doi.org/10.1210/jcem.84.10.6064

[21] Bener, A., Yousafzai, M.T., Al-Hamaq, A.O., Mohammad, A.G. and Defronzo, R.A. (2013) Parental Transmission of Type 2 Diabetes Mellitus in a Highly Endogamous Population. World Journal of Diabetes, 4, 40-46. http://dx.doi.org/10.4239/wjd.v4.i2.40

[22] Zeegers, M.P., van Poppel, F., Vlietinck, R., Spruijt, L. and Ostrer, H. (2004) Founder Mutations among the Dutch. European Journal of Human Genetics, 12, 591-600. http://dx.doi.org/10.1038/sj.ejhg.5201151

[23] Tenkanen, H., Koshinen, P., Kontula, K., et al. (1991) Polymorphisms of the Gene Encoding Cholesterol Ester Transfer Protein and Serum Lipoprotein Levels in Subjects with and without Coronary Heart Disease. Human Genetics, 87, 574-578. http://dx.doi.org/10.1007/bf00209015

[24] Mitchell, R.J., Earl, L., Williams, J., Bisucci, T. and Gasiamis, H. (1994) Polymorphisms of the Gene Coding for the Cholesteryl Ester Transfer Protein and Plasma Lipid Levels in Italian and Greek Migrants to Australia. Human Biology, 66, 13-25.

[25] Hannuksela, M.L., Liinamaa, M.J., Kesaniemi, Y.A. and Savolainen, M.J. (1994) Relation of Polymorphisms in the Cholesteryl Ester Transfer Protein Gene to Transfer Protein Activity and Plasma Lipoprotein Levels in Alcohol Drinkers. Atherosclerosis, 110, 35-44. http://dx.doi.org/10.1016/0021-9150(94)90065-5

[26] Freeman, D.J., Griffin, B.A., Holmes, A.P., et al. (1994) Regulation of Plasma HDL Cholesterol and Subfraction Distribution by Genetic and Environmental Factors. Associations between the TaqIB RFLP in the CETP Gene and Smoking and Obesity. Arteriosclerosis, Thrombosis, and Vascular Biology, 14, 336-344. http://dx.doi.org/10.1161/01.ATV.14.3.336

[27] Kondo, I., Berg, K., Drayna, D. and Lawn, R. (1989) DNA Polymorphism at the Locus for Human Cholesteryl Ester Transfer Protein (CETP) Is Associated with High Density Lipoprotein Cholesterol and Apolipoprotein Levels. Clinical Genetics, 35, 49-56. http://dx.doi.org/10.1111/j.1399-0004.1989.tb02904.x

[28] Meguro, S., Takei, I., Murata, M., et al. (2001) Cholesteryl Ester Transfer Protein Polymorphism Associated with Macroangiopathy in Japanese Patients with Type 2 Diabetes. Atherosclerosis, 156, 151-156. http://dx.doi.org/10.1016/S0021-9150(00)00606-7

[29] The Expert Committee of the Diagnosis and Classification of Diabetes Mellitus (1997) Report of the Expert Committee on the Diagnosis and Classification of Diabetes Mellitus. Diabetes Care, 20, 1183-1197. http://dx.doi.org/10.2337/diacare.20.7.1183

[30] Friedewald, W.T., Levy, R.I. and Fredrickson, D.S. (1972) Estimation of the Concentration of Low-Density Lipoprotein Cholesterol in Plasma, without Use of the Preparative Ultracentrifuge. Clinical Chemistry, 18, 499-502.

[31] Fumeron, F., Betoulle, D., Luc, G., et al. (1995) Alcohol Intake Modulates the Effect of a Polymorphism of the Cholesteryl Ester Transfer Protein Gene on Plasma High Density Lipoprotein and the Risk of Myocardial Infarction. The Journal of Clinical Investigation, 96, 1664-1671. http://dx.doi.org/10.1172/JCI118207

[32] Kawasaki, I., Tahara, H., Emoto, M., Shoji, T. and Nishizawa, Y. (2002) Relationship between TaqIB Cholesteryl Ester Transfer Protein Gene Polymorphism and Macrovascular Complications in Japanese Patients with Type 2 Diabetes. Diabetes, 51, 871-874. http://dx.doi.org/10.2337/diabetes.51.3.871

[33] Schierer, A., Been, L.F., Ralhan, S., Wander, G.S., Aston, C.E. and Sanghera, D.K. (2012) Genetic Variation in Cholesterol Ester Transfer Protein, Serum CETP Activity, and Coronary Artery Disease Risk in Asian Indian Diabetic Cohort. Pharmacogenetics and Genomics, 22, 95-104. http://dx.doi.org/10.1097/FPC.0b013e32834dc9ef

[34] McEneny, J., Blair, S., Woodside, J.V., Murray, L., Boreham, C. and Young, I.S. (2013) High-Density Lipoprotein Subfractions Display Proatherogenic Properties in Overweight and Obese Children. Pediatric Research, 74, $279-283$. http://dx.doi.org/10.1038/pr.2013.93

[35] Hirschler, V., Merono, T., Maccallini, G., Gomez Rosso, L., Aranda, C. and Brites, F. (2011) Impact of Unhealthy Lifestyle Behaviors and Obesity on Cholesteryl Ester Transfer Protein among Adolescent Males. Archives of Medical Research, 42, 53-59. http://dx.doi.org/10.1016/j.arcmed.2010.11.009 
[36] Ordovas, J.M., Cupples, L.A., Corella, D., et al. (2000) Association of Cholesteryl Ester Transfer Protein-TaqIB Polymorphism with Variations in Lipoprotein Subclasses and Coronary Heart Disease Risk: The Framingham Study. Arteriosclerosis, Thrombosis, and Vascular Biology, 20, 1323-1329. http://dx.doi.org/10.1161/01.ATV.20.5.1323

[37] Park, K.W., Choi, J.H., Kim, H.K., et al. (2003) The Association of Cholesteryl Ester Transfer Protein Polymorphism with High-Density Lipoprotein Cholesterol and Coronary Artery Disease in Koreans. Clinical Genetics, 63, 31-38. http://dx.doi.org/10.1034/j.1399-0004.2003.630105.x

[38] Lopez-Rios, L., Perez-Jimenez, P., Martinez-Quintana, E., et al. (2011) Association of Taq1B CETP Polymorphism with Insulin and HOMA Levels in the Population of the Canary Islands. Nutrition, Metabolism \& Cardiovascular Diseases, 21, 18-24. http://dx.doi.org/10.1016/j.numecd.2009.06.009

[39] Bruce, C. and Tall, A.R. (1995) Cholesteryl Ester Transfer Proteins, Reverse Cholesterol Transport, and Atherosclerosis. Current Opinion in Lipidology, 6, 306-311. http://dx.doi.org/10.1097/00041433-199510000-00010

[40] Lopez-Rios, L., Novoa, F.J., Chirino, R., Varillas, F., Boronat-Cortes, M. and Wagner, A.M. (2011) Interaction between Cholesteryl Ester Transfer Protein and Hepatic Lipase Encoding Genes and the Risk of Type 2 Diabetes: Results from the Telde Study. PLoS ONE, 6, e27208. http://dx.doi.org/10.1371/journal.pone.0027208

[41] Gammon, C.S., Minihane, A.M., Kruger, R., et al. (2014) TaqIB Polymorphism in the Cholesteryl Ester Transfer Protein (CETP) Gene Influences Lipid Responses to the Consumption of Kiwifruit in Hypercholesterolaemic Men. British Journal of Nutrition, 111, 1077-1084. http://dx.doi.org/10.1017/S0007114513003437

[42] Stein, O. and Stein, Y. (1999) Atheroprotective Mechanisms of HDL. Atherosclerosis, 144, 285-301. http://dx.doi.org/10.1016/S0021-9150(99)00065-9

[43] Bernard, S., Moulin, P., Lagrost, L., et al. (1998) Association between Plasma HDL-Cholesterol Concentration and Taq1B CETP Gene Polymorphism in Non-Insulin-Dependent Diabetes Mellitus. The Journal of Lipid Research, 39, 59-65.

[44] Pillois, X., Phuong Do Thi, N., Reynaud, A., Benchimol, D., Lagrost, L. and Bonnet, J. (2009) TaqIB Polymorphism in Cholesterol Ester Transfer Protein (CETP) Gene Predicts Future Cardiovascular Death in Patients Experiencing an Acute Coronary Syndrome. Clinical Chemistry and Laboratory Medicine, 47, 1039-1046. http://dx.doi.org/10.1515/CCLM.2009.250

[45] Chang, C.K., Tso, T.K., Snook, J.T., Huang, Y.S., Lozano, R.A. and Zipf, W.B. (2001) Cholesteryl Ester Transfer and Cholesterol Esterification in Type 1 Diabetes: Relationships with Plasma Glucose. Acta Diabetologica, 38, 37-42. http://dx.doi.org/10.1007/s005920170027

[46] de Vries, R., Perton, F.G., Dallinga-Thie, G.M., et al. (2005) Plasma Cholesteryl Ester Transfer Is a Determinant of Intima-Media Thickness in Type 2 Diabetic and Nondiabetic Subjects: Role of CETP and Triglycerides. Diabetes, 54, 3554-3559. http://dx.doi.org/10.2337/diabetes.54.12.3554

[47] Li, T.Y., Zhang, C., Asselbergs, F.W., et al. (2007) Interaction between Dietary Fat Intake and the Cholesterol Ester Transfer Protein TaqIB Polymorphism in Relation to HDL-Cholesterol Concentrations among US Diabetic Men. The American Journal of Clinical Nutrition, 86, 1524-1529.

[48] Bloomfield, D., Carlson, G.L., Sapre, A., et al. (2009) Efficacy and Safety of the Cholesteryl Ester Transfer Protein Inhibitor Anacetrapib as Monotherapy and Coadministered with Atorvastatin in Dyslipidemic Patients. American Heart Journal, 157, 352-360. http://dx.doi.org/10.1016/j.ahj.2008.09.022

[49] Krauss, R.M., Pinto, C.A., Liu, Y., Johnson-Levonas, A.O. and Dansky, H.M. (2015) Changes in LDL Particle Concentrations after Treatment with the Cholesteryl Ester Transfer Protein Inhibitor Anacetrapib Alone or in Combination with Atorvastatin. Journal of Clinical Lipidology, 9, 93-102. http://dx.doi.org/10.1016/j.jacl.2014.09.013

[50] He, B.M., Zhao, S.P. and Peng, Z.Y. (2013) Effects of Cigarette Smoking on HDL Quantity and Function: Implications for Atherosclerosis. Journal of Cellular Biochemistry, 114, 2431-2436. http://dx.doi.org/10.1002/jcb.24581

\section{Abbreviations}

Apo, apolipoprotein; BMI, body mass index; CE, cholesteryl esther; CVD, cardiovascular disease; CETP, cholesteryl ester transfer protein; FPG, fasting plasma glucose; HbA1c, glycated haemoglobin; HDL, high density lipoprotein; LDL, low density lipoprotein; OR, odds ratio; SNP, single nucleotide polymorphism; T2DM, type 2 diabetes; TG, triglycerides; TC, total cholesterol; WHR, waist-hip ratio 
Supplementary Table 1. Effect of Taq1B CETP genotypes on CVD risk of the study population ${ }^{\mathrm{a}}$.

\begin{tabular}{ccccccc}
\hline & & B1B1/B1B2 & & \multicolumn{3}{c}{ B2B2 } \\
\hline Variables & $\begin{array}{c}\text { Control } \\
\mathbf{n}=\mathbf{2 0}\end{array}$ & $\begin{array}{c}\text { T2DM } \\
\mathbf{n}=\mathbf{7 2}\end{array}$ & $\boldsymbol{p}$ & $\begin{array}{c}\text { Control } \\
\mathbf{n}=\mathbf{2}\end{array}$ & $\begin{array}{c}\text { T2DM } \\
\mathbf{n}=\mathbf{8}\end{array}$ & $\boldsymbol{p}$ \\
\hline Age (years) & $56.1 \pm 9.8$ & $58.7 \pm 7.2$ & 0.269 & $47.0 \pm 1.4$ & $53.2 \pm 7.5$ & 0.224 \\
Smoking Status & $12(60 \%)$ & $22(30.5 \%)$ & - & $2(100 \%)$ & $3(37.5 \%)$ & - \\
BMI (kg/m $)$ & $27.5 \pm 4.7$ & $30.6 \pm 3.7$ & 0.002 & $24.2 \pm 1.5$ & $31.7 \pm 2.7$ & 0.003 \\
WHR & $0.78 \pm 0.09$ & $0.94 \pm 0.06$ & $<0.0001$ & $0.67 \pm 0.02$ & $0.92 \pm 0.06$ & $<0.0001$ \\
SBP & $126.1 \pm 10.2$ & $141.1 \pm 20.8$ & 0.002 & $122.8 \pm 11.7$ & $135.8 \pm 19.2$ & 0.181 \\
AI & $4.1 \pm 0.2$ & $6.15 \pm 1.3$ & $<0.0001$ & $4.3 \pm 0.6$ & $4.4 \pm 0.7$ & 0.721 \\
TC (mg/dL) & $176.4 \pm 30.8$ & $226.5 \pm 47.2$ & $<0.0001$ & $212.0 \pm 15$ & $278.6 \pm 50$ & 0.03 \\
TG (mg/dL) & $126.6 \pm 11.2$ & $278.5 \pm 98.6$ & $<0.0001$ & $122.7 \pm 12.8$ & $290.7 \pm 85.2$ & 0.002 \\
LDL-C (mg/dL) & $99.5 \pm 15.5$ & $135.8 \pm 22.1$ & $<0.0001$ & $101.5 \pm 3$ & $141.6 \pm 22.1$ & 0.006 \\
HDL-C (mg/dL) & $44.7 \pm 1.7$ & $38.9 \pm 5.3$ & $<0.0001$ & $49.9 \pm 3.5$ & $61.1 \pm 12.3$ & 0.002 \\
FPG (mg/dL) & $88.4 \pm 9.9$ & $192.6 \pm 50.2$ & $<0.0001$ & $84.7 \pm 6.7$ & $182.4 \pm 39.5$ & 0.0007 \\
HOMA-IR & $2.46 \pm 1.1$ & $6.2 \pm 5.4$ & 0.002 & $1.0 \pm 0.3$ & $4.4 \pm 0.78$ & 0.0002 \\
INS (mU/ml) & $11.5 \pm 2.9$ & $18.0 \pm 10.7$ & 0.003 & $6.8 \pm 3.0$ & $19.6 \pm 7.0$ & 0.005 \\
HbA1c & $5.6 \pm 0.6$ & $8.6 \pm 2.4$ & $<0.0001$ & $5.2 \pm 0.4$ & $8.2 \pm 1.8$ & 0.009 \\
\hline
\end{tabular}

${ }^{\mathrm{a}}$ Data shown as percentage of the total, absolute values and mean values \pm SD. ${ }^{\mathrm{b}}$ Abbreviations used here are: AI, atherogenic index; Apo, apolipoprotein; BMI, body mass index; FPG, fasting plasma glucose; HbA1c, glycated hemoglobin; HDL-C, high-density lipoprotein-cholesterol; HOMA-IR, homeostasis model assessment-insulin resistance index; INS, fasting plasma insulin; LDL-C, low density lipoprotein-cholesterol; SBP, systolic blood pressure; TC, total cholesterol; TG, triglycerides; WHR, waist/hip ratio. 